\title{
Analysis of the Performance Characteristics of ZnO Nanoparticles' Dispersed Polyester Oil
}

\author{
V. P. Suresh Kumar, ${ }^{1}$ N. Manikandan, ${ }^{1}$ N. Nagaprasad, ${ }^{2}$ Jule LetaTesfaye, ${ }^{3,4}$ \\ and Ramasamy Krishnaraj $\mathbb{D}^{4,5}$ \\ ${ }^{1}$ Department of Mechanical Engineering, P.A. College of Engineering and Technology, Pollachi - 642002, Tamilnadu, India \\ ${ }^{2}$ Department of Mechanical Engineering, ULTRA College of Engineering and Technology, Madurai - 625104, Tamilnadu, India \\ ${ }^{3}$ Department of Physics, College of Natural and Computational Science, Dambi Dollo University, Dembi Dollo, Ethiopia \\ ${ }^{4}$ Centre for Excellence-Indigenous Knowledge, Innovative Technology Transfer and Entrepreneurship, \\ Dambi Dollo University, Dembi Dollo, Ethiopia \\ ${ }^{5}$ Department of Mechanical Engineering, College of Engineering, Dambi Dollo University, Dembi Dollo, Ethiopia
}

Correspondence should be addressed to Ramasamy Krishnaraj; prof.dr.krishnaraj@dadu.edu.et

Received 2 November 2021; Revised 24 January 2022; Accepted 26 January 2022; Published 3 March 2022

Academic Editor: Michele Iafisco

Copyright (c) 2022 V. P. Suresh Kumar et al. This is an open access article distributed under the Creative Commons Attribution License, which permits unrestricted use, distribution, and reproduction in any medium, provided the original work is properly cited.

\begin{abstract}
Analysis of performance characteristics of nanoparticles' dispersed oil has wide and an important role in oil industries. Zinc oxide nanoparticles are dispersed with polyester oil by using an ultrasonic vibrator and magnetic stirrer. Nanoparticles' concentration are taken as $0.1,0.3$, and $0.5 \mathrm{wt}$. \%. The ball-milling process is used to reduce the size of the nanoparticles before the preparation of nanoparticles' dispersed polyester oil (NPDP). Spherical shape particles with an average size of $40 \mathrm{~nm}$ are achieved for unmilled nanoparticles, whereas spherical shape particles with an average size of $30 \mathrm{~nm}$ are achieved for ball-milled nanoparticles. Pin on disc analysis shows the coefficient of friction of unmilled and ball-milled NPDP. Ball-milled NPDP results in a lesser coefficient of friction. Thermal conductivity of unmilled and ball-milled NPDP is finalized through the transient hot-wire method. Ball-milled NPDP enhances the thermal conductivity of base polyester oil than the usage of unmilled NPDP in polyester oil. In this study, the assessment and optimization of nanoparticle concentration, temperature, and ball-milling processes of nanoparticles are also carried out using the design of experiment (Doe) approach. The $L_{9}$ orthogonal array-based full factorial design is used for the best optimization result. The response tables with graphs and optimal results have been obtained through the Taguchi method.
\end{abstract}

\section{Introduction}

Nanolubricants are playing an essential role in friction and wear reduction through the accumulation of nanoparticles. In an automobile, friction is created in an engine through the moving components, and it is produced more heat. Lubricants are used to reduce the frictional heat and the wear between the contacting surfaces with each other. Many of the experimental investigations have been focused on enhancing the performance of lubrication. One of the methods is to mix the nanoparticle additives into the general lubricants, and it is used to minimize friction and wear. The friction and wear between the surfaces of contact mainly depend on the shape, size, and concentration of the nanoparticles which are added into the lubricating oil. It is confirmed through the study, which is conducted in copper nanoparticles mixed with lubrication oil. Tribological properties and coefficient of friction have been studied in copper nanoparticles [1]. The effect of nanoparticles with $\mathrm{TiO}_{2}$-based lubricant additives has been investigated on a load-carrying capacity of a journal bearing. The results have been shown that the load-carrying capacity was increased in journal bearing using $\mathrm{TiO}_{2}$ nanoparticle lubricants compared to the oils without nanoparticles [2]. The experimental tribological investigation was conducted on lubricant oil containing boron nitride nanoparticles through atomic force microscopic SEM and 
EDAX. Excellent tribological behaviors have been attained on the worn surface using boron nitride nanoparticles-based lubricant oil [3].

The tribological properties of nanofluid is depends on various parameters such as concentration of particle, type of particle, and producing methods. The efficient analyses of the complex system were carried out using statistical experimental design [4] and the Taguchi method. In the Taguchi method, the variation of the activities has been reduced through robust design. The objective of this technique was applied to produce products with high quality at a low price to the user. The proposed experimental design is based on the Taguchi method with an orthogonal array approach used to define the factors and their various levels. It permits the collection of the data to determine the most influential factor which affects the responses. Evaluation of variance with respect to the experimental data from the Taguchi techniques can be utilized to prefer new factor levels to optimize the efficiency characteristic [5].

Robust design is an essential technique for enhancing product quality, manufacturability, and reliability at the possible least price. In 1980, the introduction of Taguchi's robust approach led the major American industries to improve quality manufacturing process style. The robust design approach is to make the product perform its maximum efficiency by reducing the unnecessary deviations in the functionality of the component [6]. The small-sized electronic industries faced technical hurdles and stagnation in efforts to reduce the temperature in integrated circuits. The traditional convective cooling technique was assumed as unsuitable because of its huge required space to regulate the temperature of the integrated circuit, which was considered as impractical. Hence, it became imperative to make temperature transmission arrangements with high-conductivity materials to transfer the heat quickly and substituted with exterior atmosphere $[7,8]$. An integral approach was required to address the problem, which could assist in designing an efficient heat transfer structure. This might be achieved by using high-conductivity materials, which not only benefit the temperature control but also reduce the consumption of materials and production costs. This led to further miniaturization for efficient heat transfer. High thermal conductivity particles of nanoscales have become the candidate material for cooling the integrated circuits. However, researchers faced the hindrance in finding the thermal conductivity of the nanoparticle mixed in fluid $[9,10]$. Nanoparticle concentration is also used in the automobile engine for the cooling process [11]. Due to the electrical conductivity of the nanofluids, the transient hot wire is the most suitable method for the measurement of thermal conductivity [12]. Heat transfer has been analyzed in pin-fin material with microcoated fin and observed that it increased the rate of heat transfer [13]. In the following process, the nanoparticles with a concentration of $0.10 \%, 0.30 \%$, and $0.50 \%$ are mixed with the refrigeration oil named polyester oil with the help of a magnetic stirrer. The result shows the enrichment of thermal conductivity by adding nanoparticles with the base fluid. In order to check the result, we have taken an optimization process. The optimization process leads to the same value as the experimental value. It has also been optimized for the thermal conductivity process of water with the nanoparticle concentration, and the result has also been reviewed [14]. Multiresponse optimization was studied in minimum quantity lubrication of turning on Haynes alloy using Taguchi-based GRA [15]. Rheological behavior and their correlations with thermal conductivity and viscosity of oil-based nanofluids have been investigated [16]. Taguchi optimization and analysis of variance have been studied in the machining of duplex brass $[17,18]$. The Taguchi method and the effect of $\mathrm{S} / \mathrm{N}$ ratio on quality characteristics have been investigated [19]. Nanoparticle concentration and its effect were analyzed in turning of EN8 steel [20]. Thermal conductivity has been enhanced through zirconium oxide-based nanoparticles [21].

In the present concept, tribological properties of the polyester oil are processed with the accumulation of unmilled and ball-milled $\mathrm{ZnO}$ nanoparticles of $0.1,0.3$, and 0.5 wt.\% concentration with the aid of a pin-on-disc tribometer under different controlled conditions. Thermal conductivity of the synthesized unmilled and ball-milled NPDP with varying the temperature $\left(40,50\right.$, and $\left.60^{\circ} \mathrm{C}\right)$ and concentration of the nanoparticles $(0.1,0.3$, and $0.5 \mathrm{wt}$. \%) are also investigated. The obtained experimental results are verified with the results of the optimization technique Taguchi method.

\section{Processing of Material for Experimentation}

2.1. Grinding of Particles. Initially, the nanoparticles are purchased from sigma Aldrich company, USA. Zinc oxide nanoparticles played an important role in polyester oil. The size of the particles is processed under a ball mill (RETSCH, PM 100) for 15 hours at $340 \mathrm{rpm}$. The particle size has been reduced through tungsten carbide balls. The ball mill is operated in a clockwise and anticlockwise rotation for the starting period to control or regulate the feed of particles. After that, it is operated at high speed.

2.2. Microscopic View. The microscopic views of unmilled and ball-milled nanoparticles using TEM results are shown in Figure 1(a) at specified scale size and Figure 1(b) shows the result of EDX test and XRD values of nanoparticles. It specified the development of globular nanoparticles with different ranges of size between $30 \mathrm{~nm}$ and $60 \mathrm{~nm}$ which is achieved for unmilled particles. The size between $20 \mathrm{~nm}$ and $40 \mathrm{~nm}$ is achieved from ball-milled particles.

\subsection{Synthesis of Nanoparticles' Dispersed Polyester Oil.} The required mass concentration percentage is $0.1,0.3$, and 0.5 wt. \% of unmilled and ball-milled zinc oxide nanoparticles are diffused into pure polyester oil with the aid of an ultrasonic vibrator and magnetic stirrer to obtain NPDP. The prepared samples are appropriately labeled and shown in Figure 2 ( $\mathrm{i}$ and ii). 

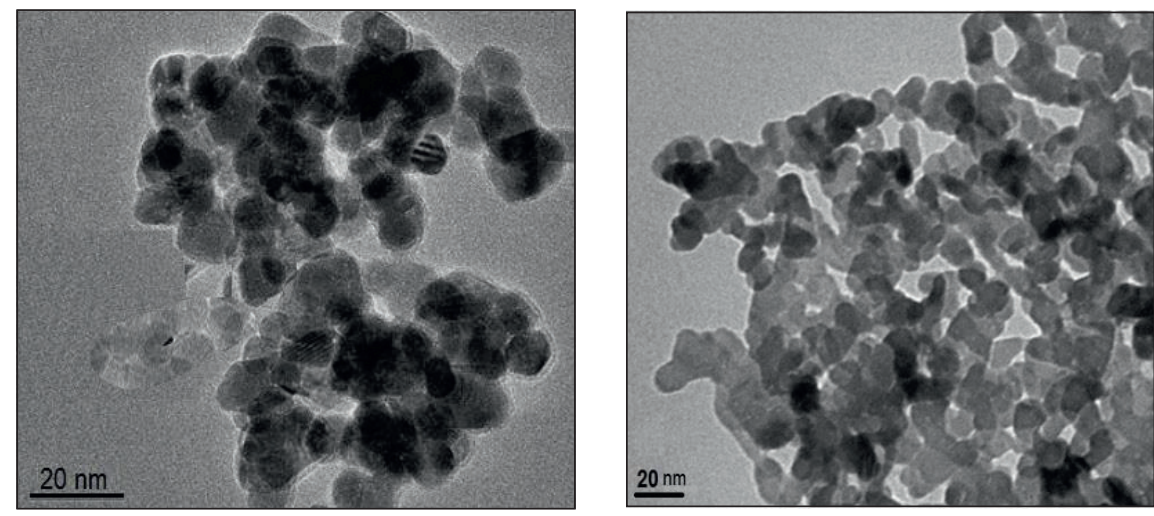

(a)

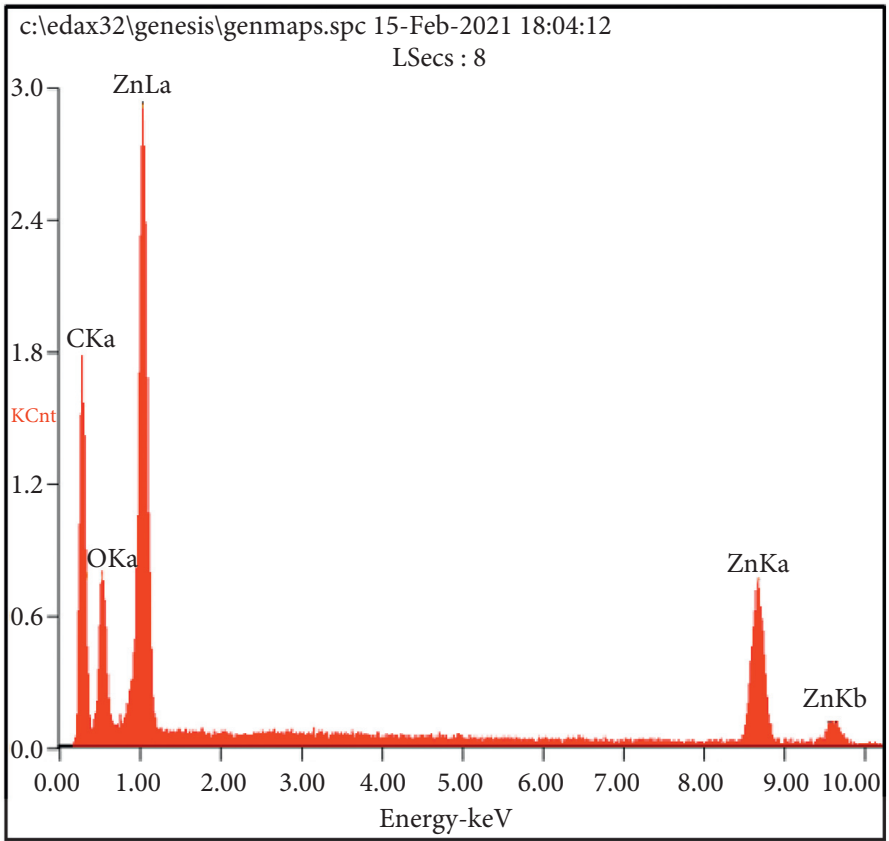

\begin{tabular}{|c|c|c|}
\hline Element & $W t \%$ & $A t \%$ \\
\hline$C K$ & 52.91 & 76.43 \\
\hline OK & 13.51 & 14.65 \\
\hline$Z n K$ & 33.58 & 08.91 \\
\hline Matrix & Correction & ZAF \\
\hline
\end{tabular}

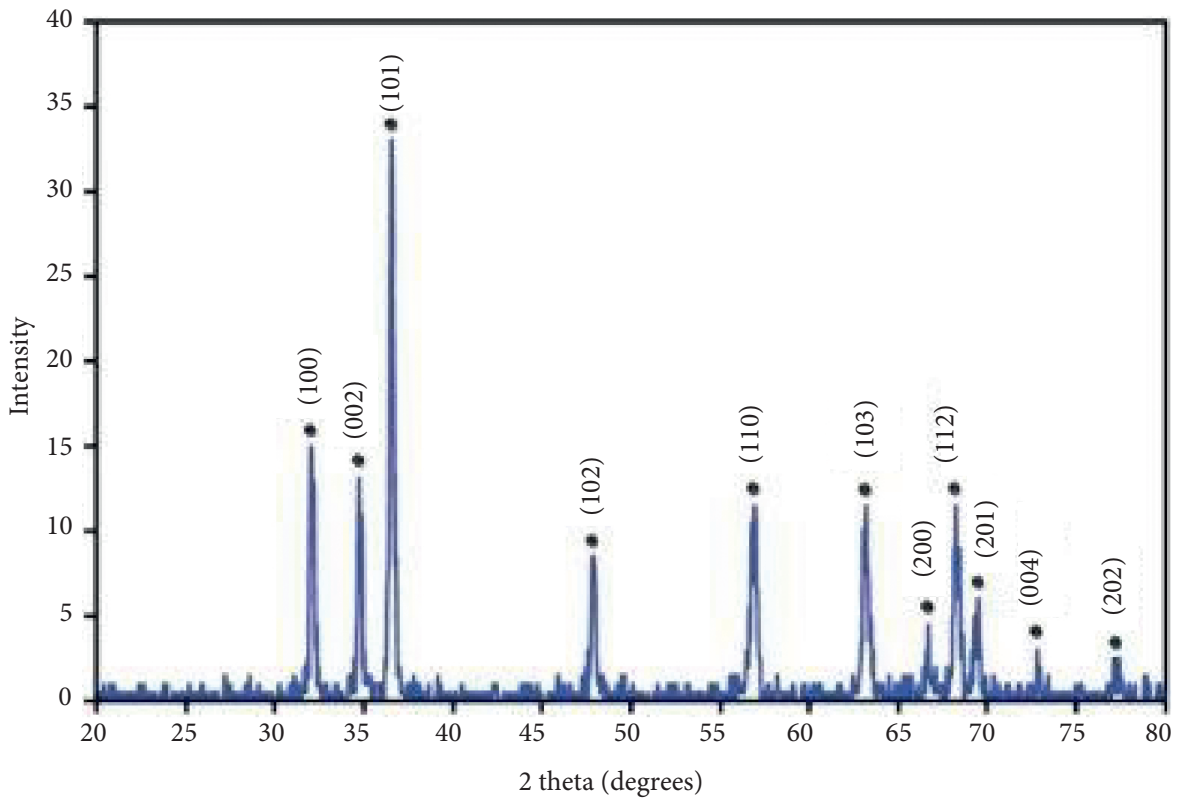

(b)

FIgure 1: (a) TEM images of nanoparticles: (i) unmilled and (ii) ball milled. (b) EDX test result and XRD images. 

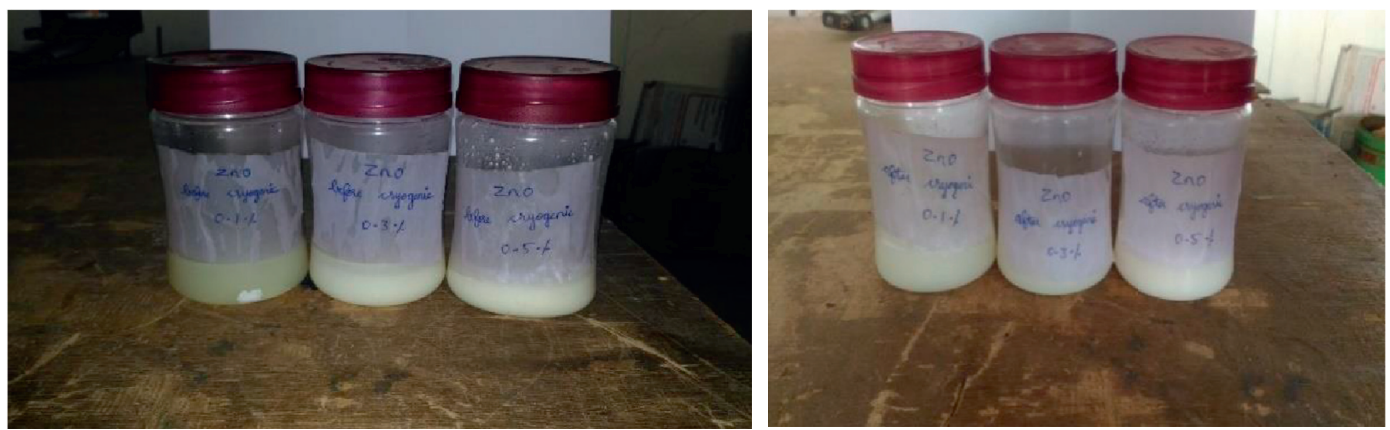

(a)
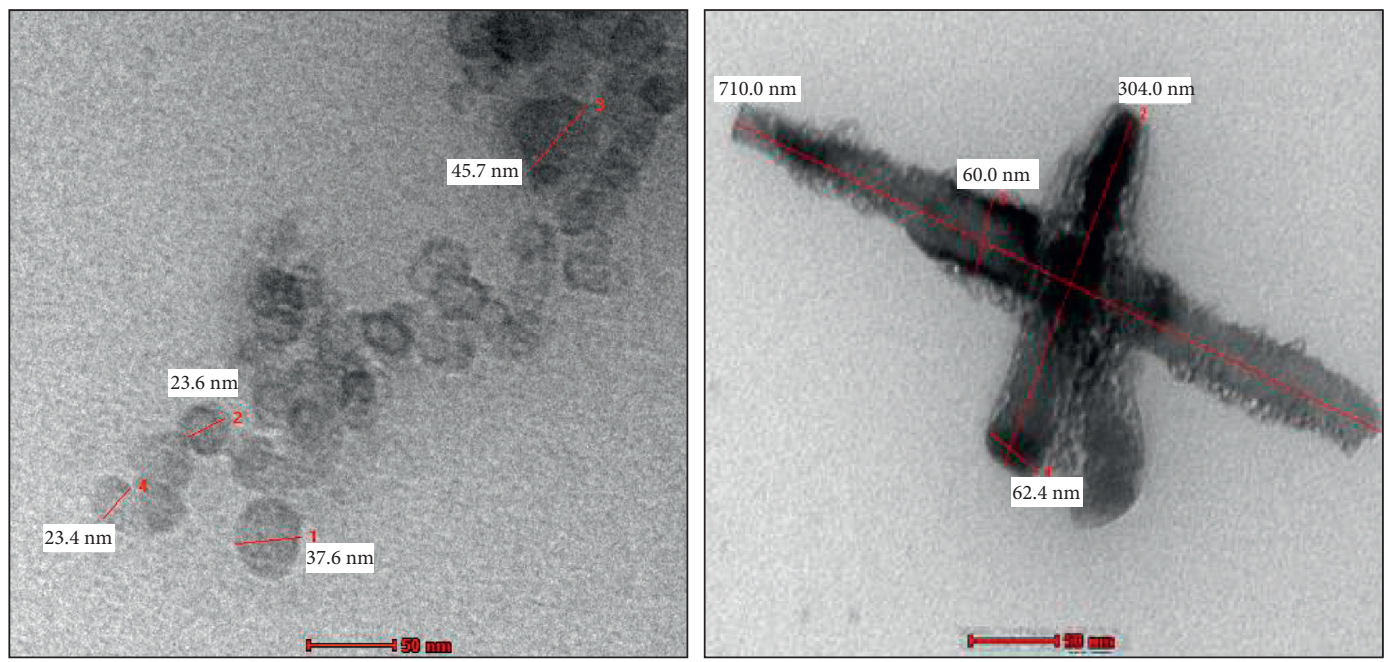

(b)

FIGURE 2: (a) Photographs of NPDP with (i) unmilled nanoparticles and (ii) ball-milled nanoparticles. (b) TEM images of NPDP mixed with oil: (i) ball-milled nanoparticles and (ii) unmilled nanoparticles

\section{Results and Discussion}

Pin on disc apparatus is used to analyze the coefficient of friction of the synthesized NPDP. The transient hot-wire method is employed to compute the thermal conductivity of the samples. The results are discussed in the following sections.

\subsection{Thermal Conductivity Analysis of NPDP. A nichrome} wire of diameter $0.38 \mathrm{~mm}$ is utilized for the hot wire. Initially, the nichrome wire is immersed in the nanofluid, which was kept in equilibrium with the surroundings. The temperature and the output voltage have been increased through the electric resistance of the nichrome wire, and it is measured by an analog to digital converter. The thermal conductivity parameters of NPDP with unmilled and ballmilled nanoparticles are measured by using the apparatus shown in Figure 3, and its values are calculated by using [11]

$$
k=\frac{q}{4 \pi\left(T_{2}-T\right)_{1}} \ln (t)
$$

where $\mathrm{k}$ is thermal conductivity of fluid, $q$ is the amount of heat, $T_{1}$ is temperature (initial), $T_{2}$ is temperature (final), and $t$ is time taken to increase the tempeature.
The calculation procedures are as follows: $\mathrm{Q}=\mathrm{V} * \mathrm{I}$, $\mathrm{V}=4 \mathrm{~V}, \quad \mathrm{I}=0.57 \quad \mathrm{~A}, \quad q=2.28 \mathrm{~W}, \quad T_{2}=40, \quad T_{1}=35$, and $t=42.81 \mathrm{~s}$.

The transient hot-wire thermal conductivity measurement method was trusted to gauge the thermal conductivity of solids and liquids. It functions on the principle that a material's electric resistivity was directly linked to its temperature. An extended thin metallic wire was suspended either vertically or horizontally in the materials whose thermal conductivity was usually to be calculated. The wire was energized through continuous heat supplied through continuous electrical power. Hence, the resistance of the suspended wire or the voltage drop has been modified until it reaches cryogenic temperature. The lead-based fluid additives were added to the nanoparticle to improve their concentration [22]. The nanofluid particles were utilized to improve the heat transfer [23-26]. The thermal conductivity of the synthesized NPDP before and after the ball-milling process is tabulated in Table 1.

3.2. Coefficient of Friction Analysis of NPDP. A pin on the disc tribometer is shown in Figure 4. It has a stationary pin and a rotating disc. The pin is processed over the rotating disc and is shaped with spherical tips along with contact 


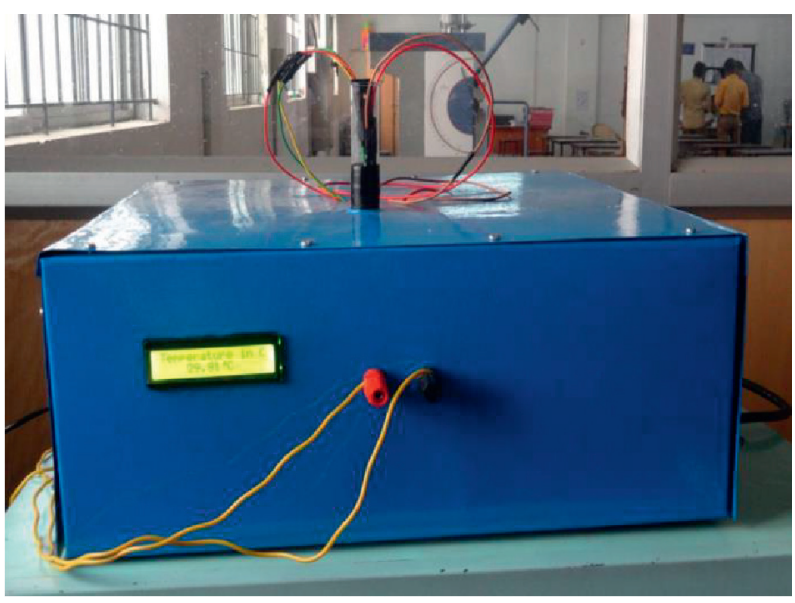

FIGURE 3: Thermal conductivity-measuring apparatus.

geometry. The coefficient of friction is estimated through the ratio between frictional force and the applied load. A pin-ondisc tribometer is used to analyze the tribological properties of the synthesized samples at different volumetric percentages as compared to ASTM G99. The test is carried out at $25^{\circ} \mathrm{C}$ with a velocity of $0.314 \mathrm{~m} / \mathrm{s}$ and an applied load of $4 \mathrm{~kg}$, $5 \mathrm{~kg}$, and $6 \mathrm{Kg}$. The friction was measured by mass loss using a precision balance of $1 \mathrm{~g}$. Meanwhile, the values of the cohesion measure have also been recorded. Three test runs are performed and recorded for each test condition [27], and also, the specification of apparatus is given in Table 2 .

The obtained results for NPDP with 0.3 wt. \% unmilled and ball-milled nanoparticles are shown graphically in Figure 5(a) and 5(b), and the average coefficient of friction values of NPDP with $0.1,0.3$, and 0.5 wt. \% of ball-milled nanoparticles is tabulated in Table 3.

From Figure 5(a) and 5(b), it is clearly shown that the coefficient of friction $(\mathrm{CoF})$ varied with the increase in load for polyester oil without nanoparticles. The variation in $\mathrm{CoF}$ for a given time of $0-3600$ s is noticed to be higher for the load of $4 \mathrm{~kg}$ and compared with $5 \mathrm{~kg}$ or $6 \mathrm{~kg}$ loads. Figure 5(a) and 5(b) shows the higher decrease in coefficient of friction of polyester oil with 0.3 wt. \% of ball-milled nanoparticles than that of NPDP with unmilled nanoparticles for loads 4, 5, and $6 \mathrm{~kg}$. From Table 3, a higher percentage decrease in coefficient of friction is achieved for NPDP with 0.3 wt. \% ball-milled nanoparticles than that of NPDP with 0.1 and 0.5 wt. \% of nanoparticles. This study shows that dispersing ball-milled $\mathrm{ZnO}$ nanoparticles in the base polyester oil has produced better lubrication properties, minimizing the friction and wear rate.

3.3. Taguchi Approach. Taguchi [28] developed a method to predict the results based on the design of experiments through different parameters. Taguchi method-based S/N ratio was used to decide the quality characteristics of the processing parameter. An increased $\mathrm{S} / \mathrm{N}$ specified better quality characteristics. The adjustment of the $\mathrm{S} / \mathrm{N}$ ratio and its process functionality has been discussed [29]. Taguchi proposed a structure of two separate experimental plans for the sound and control factors. No interactions were made among control factors and proposed responses' factors [30]. The experimental data and the thermal conductivity equation for the nanoparticle concentration were the main factors used in MINITAB software. The effect of the S/N ratio on response was the main criteria for the optimization problems [31]. According to Tables 4-6, ANOVA is used to determine the most significant parameter affecting output quality and characteristics by using quantities such as degree of freedom (f), sum of squares (SS), variance (V), percent contribution of each parameter (F-ratio), and contribution ratio or contribution of variance.

3.4. Before Ball-Milled Process. The $L_{9}$ orthogonal array experimental design was used in Taguchi approach to estimate the optimal parameters. The better criterion was chosen to obtain the better thermal conductivity of oil. Based on it, the signal-to-noise ratio $(\mathrm{S} / \mathrm{N})$ and means were estimated. The effect of input factors has a linear relation with the response, such as thermal conductivity. Determination of $\mathrm{S} / \mathrm{N}$ ratio and means are shown in Table 7.

Figure 6 shows the S/N ratio effect on thermal conductivity before the ball-milled process. As per "higher the better" condition of the $\mathrm{S} / \mathrm{N}$ ratio, the high peak points were considered from the plot. The optimal thermal conductivity was achieved at a temperature of $60^{\circ} \mathrm{C}$, oil concentration with nanofluid of $0.5 \%$, and sonication time of 45 minutes. The process input factors and their contribution to thermal conductivity are shown in Table 5 . The temperature has been produced $71.26 \%$ of the effect on thermal conductivity. 
TABLE 1: Experimental data for thermal conductivity of NPDP.

\begin{tabular}{lcccccc}
\hline S.No & $\begin{array}{c}\text { Temperature } \\
\left({ }^{\circ} \mathrm{C}\right)\end{array}$ & $\begin{array}{c}\text { Concentration } \\
(\%)\end{array}$ & $\begin{array}{c}\text { Sonication time } \\
(\mathrm{min})\end{array}$ & $\begin{array}{c}\text { Unmilled } \\
\text { Thermal conductivity } \\
(\mathrm{W} / \mathrm{mK})\end{array}$ & $\begin{array}{c}\text { Ball milled } \\
\text { Thermal conductivity } \\
(\mathrm{W} / \mathrm{mK})\end{array}$ & $\begin{array}{c}\text { Differences } \\
\text { Thermal conductivity } \\
(\mathrm{W} / \mathrm{mK})\end{array}$ \\
\hline 1 & 40 & 0.1 & 30 & 0.143 & 0.163 & 0.020 \\
2 & 40 & 0.3 & 45 & 0.158 & 0.174 & 0.016 \\
3 & 40 & 0.5 & 60 & 0.160 & 0.170 & 0.017 \\
4 & 50 & 0.1 & 45 & 0.151 & 0.182 & 0.019 \\
5 & 50 & 0.3 & 60 & 0.166 & 0.187 & 0.016 \\
6 & 50 & 0.5 & 30 & 0.170 & 0.190 & 0.017 \\
7 & 60 & 0.1 & 60 & 0.190 & 0.210 & 0.020 \\
8 & 60 & 0.3 & 30 & 0.194 & 0.213 & 0.019 \\
9 & 60 & 0.5 & 45 & & \\
\hline
\end{tabular}

From the results of thermal conductivity of unmilled and ball-milled NPDP, it increased with the concentration of the nanoparticles and temperature. The thermal conductivity of ball-milled NPDP is higher than that of unmilled NPDP.

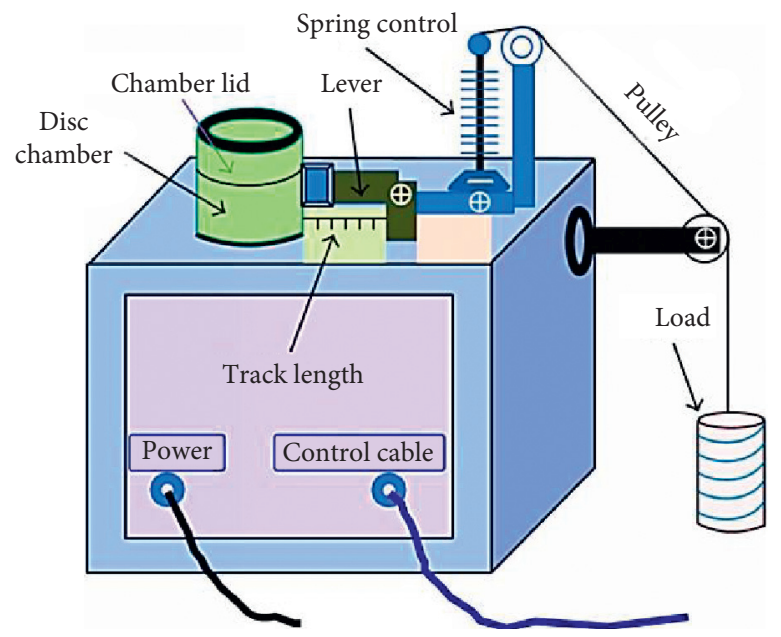

FIgURE 4: Pin on disc apparatus.

TABLe 2: The specifications of pin on disc apparatus.

\begin{tabular}{lcr}
\hline Sl. no & Description & Parameters with units \\
\hline 1. & Load & $5 \mathrm{~N}$ to $200 \mathrm{~N}$ \\
2. & Disc dimensions & $165 \mathrm{~mm} \times 8 \mathrm{~mm}$ \\
3. & Speed of disc & $200 \mathrm{rpm}$ to $2000 \mathrm{rpm}$ \\
4. & Pin diameter used & $3 \mathrm{~mm}, 6 \mathrm{~mm}$, and $10 \mathrm{~mm}$ \\
5. & Lubrication & Recirculation system \\
6. & Frictional force & Up to 200N \\
\hline
\end{tabular}

3.5. After Ball-Milled Process. The experimental design was followed by $L_{9}$ orthogonal array, and it was used to evaluate the optimal parameter of thermal conductivity after the ball-milled process. The better thermal conductivity of oil was achieved on the basis of the larger better criterion. Based on it, the signal-to-noise ratio (S/ $\mathrm{N}$ ) and means were estimated. Determination of $\mathrm{SN}$ ratio and means after the cryogenic treatment are shown in Table 6.
Figure 7 shows the $\mathrm{S} / \mathrm{N}$ ratio effect on thermal conductivity after the ball-milled process. As per "larger the better" condition of the $\mathrm{S} / \mathrm{N}$ ratio, the high peak points were considered from the plot. The optimal thermal conductivity was achieved at a temperature of $60^{\circ} \mathrm{C}$, oil concentration with nanofluid of $0.5 \%$, and sonication time of 30 minutes. The process input factors and their contribution to thermal conductivity after the ballmilled process are shown in Table 7. The temperature has produced a $75.48 \%$ of the effect on thermal conductivity. 


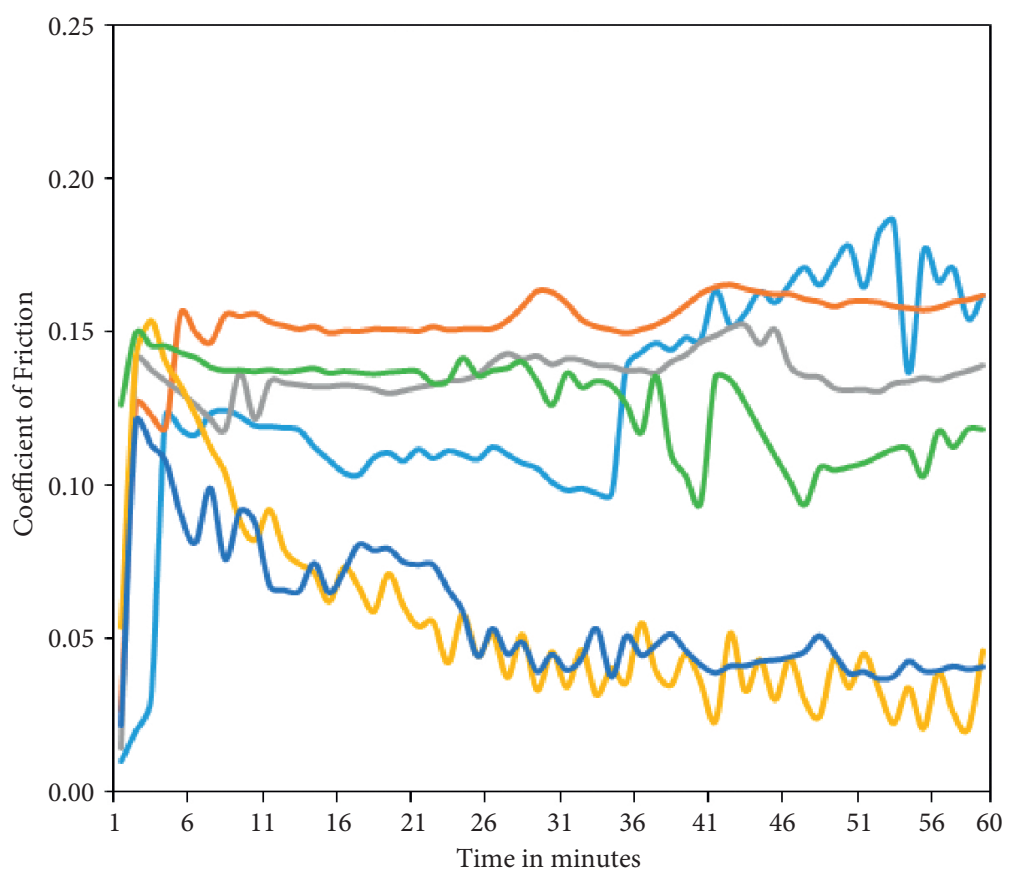

Without nano oil $4 \mathrm{~kg}$

- Without nano oil $5 \mathrm{~kg}$

- Without nano oil $6 \mathrm{~kg}$

— With nano $0.3 \mathrm{wt} \%$ Zno2 Before Ballmill process $4 \mathrm{~kg}$

— With nano $0.3 \mathrm{wt} \% \mathrm{Zno} 2$ Before Ballmill process $5 \mathrm{~kg}$

— With nano $0.3 \mathrm{wt} \%$ Zno2 Before Ballmill process $6 \mathrm{~kg}$

(a)

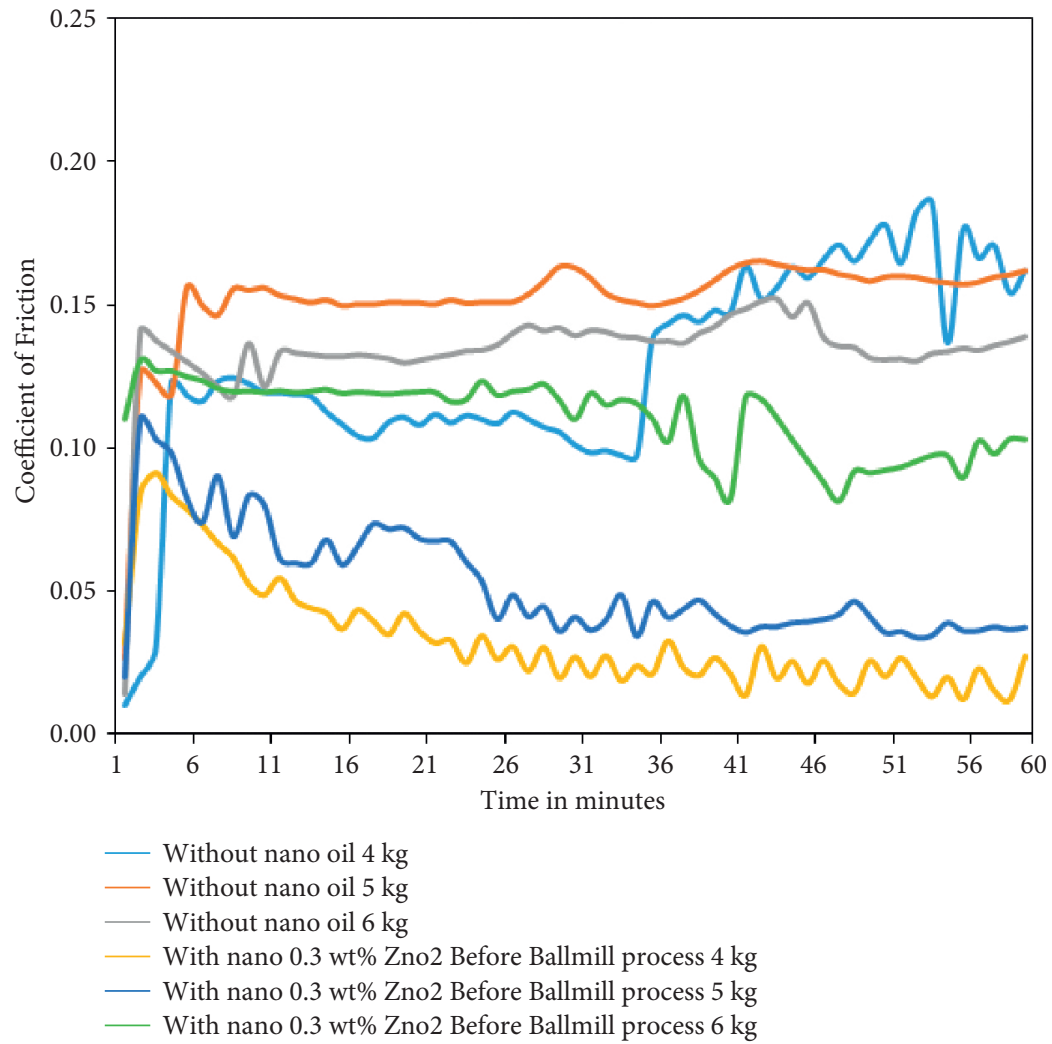

(b)

FIgURE 5: (a) Coefficient of friction values of NPDP with $0.3 \mathrm{wt}$ \% unmilled nanoparticles. (b) Coefficient of friction values of NPDP with 0.3 wt. \% ball-milled nanoparticles. 
TABLE 3: Coefficient of friction values of NPDP with different wt. \% of $\mathrm{ZnO}$ ball-milled nanoparticles at various loads for 1 hour duration.

\begin{tabular}{lcccc}
\hline Load $(\mathrm{kg}) /$ force $(\mathrm{N})$ & CoF $($ grade 60 oil) & CoF $(0.1$ wt. \%) & CoF $(0.3$ wt. \%) & CoF $(0.5$ wt. \%) \\
\hline $4.0 / 39 \mathrm{~N}$ & 0.102 & 0.055 & 0.023 & 0.094 \\
$5.0 / 49 \mathrm{~N}$ & 0.133 & 0.074 & 0.035 & 0.083 \\
$6.0 / 58 \mathrm{~N}$ & 0.132 & 0.099 & 0.090 & 0.097 \\
\hline
\end{tabular}

TABLE 4: Variance analysis for thermal conductivity (unmilled process).

\begin{tabular}{|c|c|c|c|c|c|c|}
\hline Basis & $\mathrm{DF}$ & SS & MS & $\mathrm{F}$ & $\mathrm{P}$ & $\%$ \\
\hline Temperature & 2 & 0.001607 & 0.000803 & 1033.00 & 0.001 & 71.26 \\
\hline Concentration & 2 & 0.000641 & 0.000320 & 412.00 & 0.002 & 28.43 \\
\hline Sonication time & 2 & 0.000006 & 0.000003 & 3.57 & 0.219 & 00.27 \\
\hline Error & 2 & 0.000002 & 0.000001 & --- & --- & 00.04 \\
\hline Total & 8 & 0.002255 & --- & --- & --- & 100 \\
\hline$S=0.0008819$ & \multicolumn{2}{|c|}{$\mathrm{R}-\mathrm{Sq}=99.93 \%$} & \multicolumn{2}{|c|}{ R-Sq(Adj.) $=99.72 \%$} & \multicolumn{2}{|c|}{$\mathrm{R}-\mathrm{Sq}($ Adj. $)=98.60 \%$} \\
\hline
\end{tabular}

TABle 5: S/N ratio and means for thermal conductivity (ball-milled process).

\begin{tabular}{lcccccc}
\hline S/N ratios & & & & \multicolumn{2}{c}{ Means } \\
Level & Temperature & Concentration & Sonication time & Temperature & Concentration & Sonication time \\
\hline 1 & -15.33 & -15.19 & -14.63 & 0.1713 & 0.1743 & 0.1867 \\
2 & -14.92 & -14.51 & -14.67 & 0.1797 & 0.1887 & 0.1857 \\
3 & -13.80 & -14.35 & -14.75 & 0.2043 & 0.1923 & 0.1830 \\
Delta & 1.52 & 0.85 & 0.13 & 0.0330 & 0.0180 & 2 \\
Rank & 1 & 2 & 3 & 1 & 3 \\
\hline
\end{tabular}

TABLE 6: Variance analysis for thermal conductivity (ball-milled process).

\begin{tabular}{lccccc}
\hline Basis & DF & SS & MS & F & P \\
\hline Temperature & 2 & 0.001767 & 0.000883 & 184.91 & 0.005 \\
Concentration & 2 & 0.000543 & 0.000271 & 56.81 & 0.017 \\
Sonication time & 2 & 0.000022 & 0.000011 & 2.26 & 0.307 \\
Error & 2 & 0.000010 & 0.000005 & --- & --- \\
Total & 8 & 0.002341 & --- & --- & 00.94 \\
$S=0.0021858$ & & R-Sq $=99.59 \%$ & R-Sq(Adj.) $=98.37 \%$ & 100.39 \\
\hline
\end{tabular}

TABLE 7: S/N ratio and means for thermal conductivity (unmilled process).

\begin{tabular}{|c|c|c|c|c|c|c|}
\hline \multicolumn{4}{|c|}{$\mathrm{S} / \mathrm{N}$ ratios } & \multicolumn{3}{|c|}{ Means } \\
\hline Level & Temperature & Concentration & Sonication time & Temperature & Concentration & Sonication time \\
\hline 1 & -16.28 & 16.20 & 15.57 & 0.1537 & 0.1553 & 0.1677 \\
\hline 2 & 15.80 & 15.35 & 15.56 & 0.1623 & 0.1623 & 0.1677 \\
\hline 3 & 14.65 & 15.18 & 15.60 & 0.1853 & 0.1747 & 0.1660 \\
\hline Delta & 1.63 & 1.02 & 0.04 & 0.0317 & 0.0193 & 0.0017 \\
\hline Rank & 1 & 2 & 3 & 1 & 2 & 3 \\
\hline
\end{tabular}




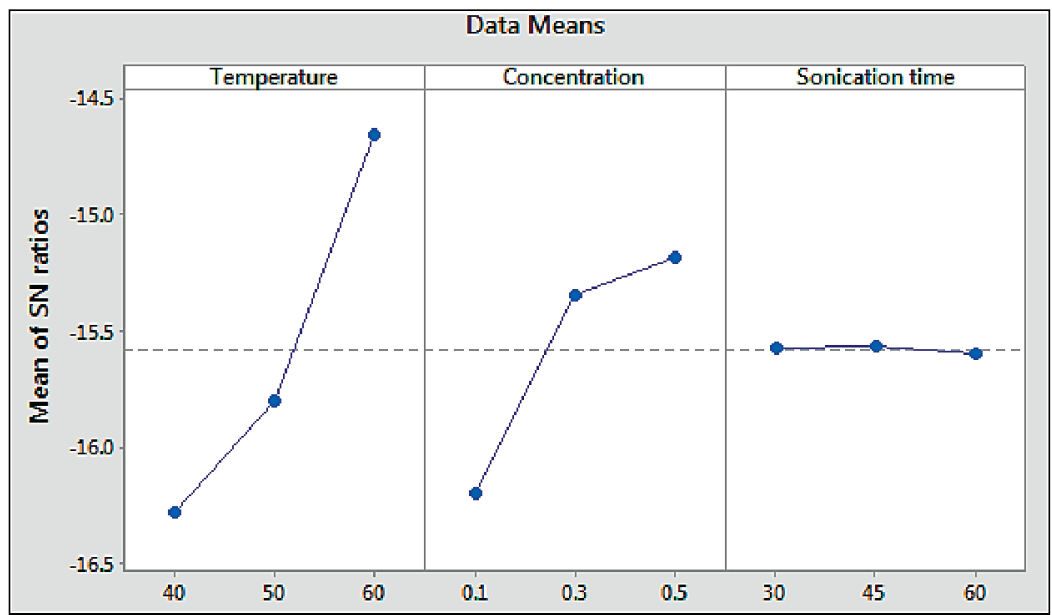

FIGURE 6: S/N ratio effect on thermal conductivity (unmilled process).

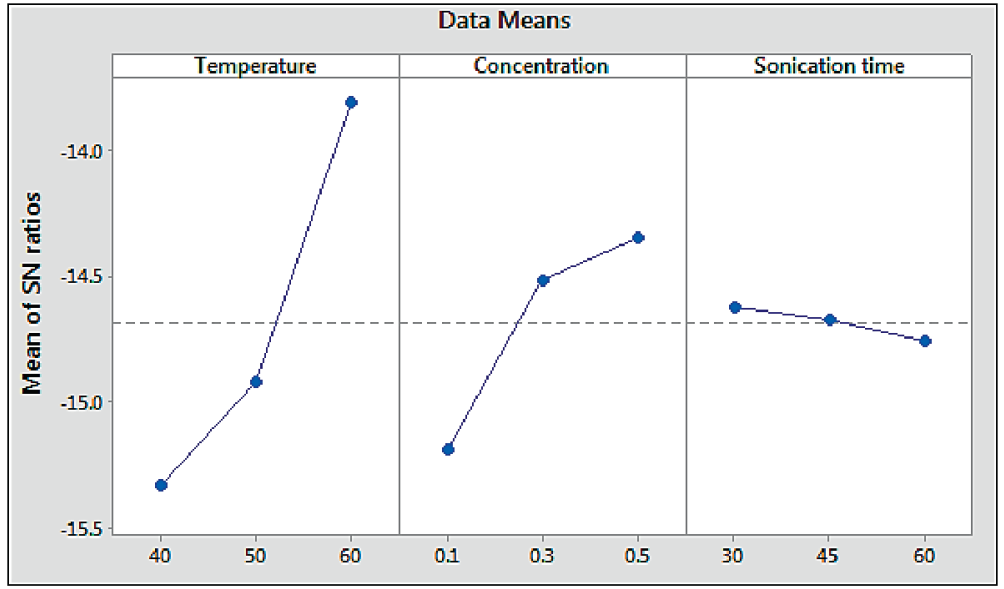

FIgURE 7: SN ratio effect for thermal conductivity (ball-milled process).

\section{Conclusions}

The thermal conductivity of nanoparticle concentrated polyester oil was investigated before and after the ballmilling process. The Taguchi method was used to determine the optimized parameter during the process. A ball-milled process and nanoparticle-based polyester oil were used to improve thermal conductivity. At the same time, the coefficient of friction has been reduced. Thermal conductivity has been improved to $0.020 \mathrm{~W} / \mathrm{mK}$ using a ball-milled process. Taguchi optimization had been used to optimize thermal conductivity parameters during the ball-milling method. The optimal thermal conductivity was achieved prior to the ball-milling process at a temperature of $60^{\circ} \mathrm{C}$, an oil concentration of 0.5 percent with a nanofluid, and a sonication time of 45 minutes. The improved thermal conductivity has been obtained after the ball-milled method at a temperature of $60^{\circ} \mathrm{C}$, a concentration of oil with nanofluid of 0.5 percent, and a sonication time of 30 minutes. In both processes, temperature was the most influential parameter on thermal conductivity (before process, $71.26 \%$, and after process, $75.48 \%$ ).

\section{Data Availability}

The data used to support the findings of this study are included within the article.

\section{Disclosure}

This study was performed as a part of the employment of the authors.

\section{Conflicts of Interest}

The authors declare that there are no conflicts of interest.

\section{References}

[1] V. Zin, F. Agresti, S. Barison, L. Colla, A. Gondolini, and M. Fabrizio, "The synthesis and effect of copper nanoparticles on the tribological properties of lubricant oils," IEEE Transactions on Nanotechnology, vol. 12, no. 5, pp. 751-759, 2013.

[2] K. G. Binu, B. S. Shenoy, D. S. Rao, and R. Pai, "A variable viscosity approach for the evaluation of load carrying capacity 
of oil lubricated journal bearing with $\mathrm{TiO} 2$ nanoparticles as lubricant additives," Procedia Materials Science, vol. 6, no. 1, pp. 1051-1067, 2014.

[3] Q. Wan, Y. Jin, P. Sun, and Y. Ding, "Tribological behaviour of a lubricant oil containing boron nitride nanoparticles," Procedia Engineering, vol. 102, pp. 1038-1045, 2015.

[4] H. T. Kim and H. Kim, "Applying the Taguchi method to the optimization for the synthesis of $\mathrm{TiO} 2$ nanoparticles by hydrolysis of TEOT in micelles," Colloids and Surfaces A: Physicochemical and Engineering Aspects, vol. 254, pp. 99-105, 2005.

[5] A. Saka, J. L. Tesfaye, L. Gudata et al., "Synthesis, characterization, and antibacterial activity of $\mathrm{ZnO}$ nanoparticles from fresh leaf extracts of apocynaceae, Carissa spinarum L. (Hagamsa)," Journal of Nanomaterials, vol. 2022, Article ID 6230298, 6 pages, 2022.

[6] K.-L. Tsui, "An overview of Taguchi method and newly developed statistical methods for robust design," IIE Transactions, vol. 24, no. 5, pp. 44-57, 1992.

[7] A. Bejan, "Constructal-theory network of conducting paths for cooling a heat generating," vol. 40, no. 4, pp. 799-816, 1997.

[8] H. Machrafi and G. Lebon, "The role of several heat transfer mechanisms on the enhancement of thermal conductivity in nanofluids," Continuum Mechanics and Thermodynamics, vol. 28, no. 5, pp. 1461-1475, 2016.

[9] J. Chandraskar, B. Vidyasagar, M. Vijendhar Reddy, and S. Sathish, "Analysis and optimization of machining parameters of EN-47 in turning by Taguchi method and MINITAB-17 software," International Journal of Engineering Research \& Technology, vol. 6, no. 4, pp. 975-981, 2017.

[10] V. P. Suresh Kumar, N. Manikandan, Y. G. Sterbin Jeso, C. Subakaran, and N. Muthukumar, "Apparatus for measuring thermal conductivity of fluids," International Journal of Scientific Engineering and Research, vol. 8, no. 4, pp. 320-323, 2017.

[11] V. P. Suresh Kumar, N. Manikandan, C. Subakaran, and Y. G. Sterbin Jeso, "An experimental effect of $\mathrm{ZnO}$ nanoparticles in SAE 20W50 oil," International Research Journal of Engineering and Technology, vol. 5, no. 3, pp. 1-5, 2018.

[12] X. Wang, X. Xu, and S. U. S. Choi, "Thermal conductivity of nanoparticle - fluid mixture," Journal of Thermophysics and Heat Transfer, vol. 13, no. 4, pp. 474-480, 1999.

[13] V. P. Suresh Kumar and N. Manikandan, "Experimental analysis of heat transfer rate in pin fin material with micro coating," International Journal of Applied Engineering Research, vol. 10, no. 19, Article ID 14386, 2015.

[14] S. Abel, J. Leta Tesfaye, N. Nagaprasad, R. Shanmugam, L. Priyanka Dwarampudi, and R. Krishnaraj, "Synthesis and characterization of zinc oxide nanoparticles using moringa leaf extract," Journal of Nanomaterials, vol. 2021, Article ID 4525770, 6 pages, 2021.

[15] M. Sarıkaya and A. Güllü, "Multi-response optimization of MQL parameters using Taguchi-based GRA in turning of difficult-to-cut alloy Haynes 25," Journal of Cleaner Production, vol. 1, pp. 1-11, 2014.

[16] S. Aberoumand, A. Jafarimoghaddam, M. Moravej, H. Aberoumand, and K. Javaherdeh, "Experimental study on the rheological behavior of silver-heat transfer oil nanofluid and suggesting two empirical based correlations for thermal conductivity and viscosity of oil based nanofluids," Applied Thermal Engineering, vol. 101, pp. 362-372, 2016.

[17] S. Marichamy, M. Saravanan, M. Ravichandran, and G. Veerappan, "Parametric optimization of EDM process on $\alpha-\beta$ brass using Taguchi approach," Russian Journal of Nonferrous Metals, vol. 57, no. 6, pp. 586-598, 2016.

[18] S. Marichamy, M. Ravichandran, B. Stalin, and S. Babu, "Optimization of abrasive water jet machining parameters for $\alpha-\beta$ brass using Taguchi methodology," FME Transactions, vol. 47, no. 1, pp. 116-121, 2019.

[19] D. Madan, K. Babu, P. G. Krishnan, S. Marichamy, and P. Ganesan, "Taguchi parametric optimization on stellite metal matrix using metal inert gas weld," Proceedings of the AIP Conference Proceedings, vol. 2283pp. 220-226, 2020.

[20] N. Mani, K. Mani, C. Mathew, and P. M. Kallanickal, "Optimization of cutting parameters \& nanoparticle concentration in CNC turning of EN8 steel using Al2O3 nanofluids as coolant," International Journal of Engineering Trends and Technology, vol. 29, no. 6, pp. 290-294, 2015.

[21] V. P. Suresh Kumar and K. M. Subaramanian, "Thermal conductivity enhancement of nano zirconium oxide using cryogenic treatment," PerspectivasEmCiencia da Informacao, vol. 22 , pp. $318-325,2017$.

[22] M. Jamil, A. M. Khan, H. Hegab et al., "Effects of hybrid Al2O3-CNT nanofluids and cryogenic cooling on machining of Ti-6Al-4V," International Journal of Advanced Manufacturing Technology, vol. 102, no. 9-12, pp. 3895-3909, 2019.

[23] S. Das, K. Bandyopadhyay, and M. M. Ghosh, "A study on thermal conductivity and stability of nanofluids containing chemically synthesized nanoparticles for advanced thermal applications," Journal of Materials Engineering and Performance, vol. 27, no. 8, pp. 3994-4004, 2018.

[24] A. Ghadimi, R. Saidur, and H. S. C. Metselaar, "A review of nanofluid stability properties and characterization in stationary conditions," International Journal of Heat and Mass Transfer, vol. 54, no. 17-18, pp. 4051-4068, 2011.

[25] A. Degefa, B. Bekele, L. T. Jule et al., "Green synthesis, characterization of zinc oxide nanoparticles, and examination of properties for dye-sensitive solar cells using various vegetable extracts," Journal of Nanomaterials, vol. 2021, Article ID 3941923, 9 pages, 2021.

[26] T.-P. Teng, "Thermal conductivity and phase-change properties of aqueous alumina nanofluid," Energy Conversion and Management, vol. 67, pp. 369-375, 2013.

[27] V. P. Suresh Kumar and K. M. Subramanian, "Influence of $\mathrm{ZnO}$ nano particles on thermos physical and tribological properties of Polyol Ester oil," Material research express, vol. 8, no. 4, Article ID 04552, 2021.

[28] M. N. Pervez, F Shafiq, Z Sarwar, M. M Jilani, and Y Cai, "Multi-response optimization of resin finishing by using a taguchi-based grey relational analysis," Materials, vol. 11, no. 426, pp. 3-19, 2018.

[29] F.-C. Wu and C.-C. Chyu, "A comparative study on Taguchi's $\mathrm{SN}$ ratio, minimising MSD and variance for nominal-the-best characteristic experiment," International Journal of Advanced Manufacturing Technology, vol. 20, no. 9, pp. 655-659, 2002.

[30] W. C. Chen and D. Kurniawan, "Process parameters optimization for multiple quality characteristics in plastic injection molding using Taguchi method, BPNN, ga, and hybrid PSO-ga," International Journal of Precision Engineering and Manufacturing, vol. 15, pp. 1583-1593, 2104.

[31] B. Bekele, A. Degefa, F. Tesgera et al., "Green versus chemical precipitation methods of preparing zinc oxide nanoparticles and investigation of antimicrobial properties," Journal of Nanomaterials, vol. 2021, Article ID 9210817, 10 pages, 2021. 